\title{
ARROIOS JAGUARÍ-MIRIM, INHADIJU E PIQUIRI EM SEU CONTEXTO GEOMORFOLÓGICO
}

\author{
Jaquari-Mirim, Inhadiju and Piquiri Streams in their \\ geomorphologic context
}

\author{
Eléia RIGHI ${ }^{1}$ \\ Luis Eduardo de Souza ROBAINA²
}

\section{RESUMO}

Este artigo objetiva o mapeamento de Unidades Geomorfológicas das Bacias Hidrográficas dos Arroios Jaguarí Mirim, Inhadiju e Piquiri, localizadas no Oeste do Rio Grande do Sul - Brasil. As análises dos dados definiram seis unidades caracterizadas como: Unidade I - Relevo de Topo Plano em Derrame Vulcânico: apresenta relevo plano com processos erosivos relativamente baixos e intemperismo; Unidade II - Colinas em Derrame Vulcânico: constituem-se as áreas suavemente onduladas sob o topo do Planalto; Unidade III Morros e Morrotes em Rocha Vulcânica: formados por relevo fortemente ondulado e com escarpas; Unidade IV - Morrotes em Arenito: compostos por morrotes isolados com origem associada à existência de arenitos coesos que mantém o relevo de topo plano; Unidade $V$ - Colinas em Arenito: relevo de colinas localizadas ao médio e baixo curso dos arroios, com ocorrência de processos erosivos acelerados gerando areais e voçorocas, às vezes com afloramentos de arenitos coesos na meia encosta ou no topo; Unidade VI - Relevo Plano em Baixa Altitude: relevo de topografia plana que predispõe os processos de dinâmica superficial gerando acumulação de sedimentos e a formação de terraços fluviais. A fragilidade dos sistemas naturais, face às intervenções antrópicas, está amplamente ligada às suas características genéticas. Desta forma, a analise geomorfológica nos estudos ambientais é uma ferramenta para o planejamento de forma sustentável nas atividades implantadas na região.

Palavras-chave: Bacias Hidrográficas; Mapeamento; Unidades Geomorfológicas; Abstract.

\begin{abstract}
The present article aims at the mapping of the Geomorphologic Units of the Hydrographic Basins of the Jaguari Mirim, Inhadiju, and Piquiri Streams, located in the western part of Rio Grande do Sul - Brazil. Data analysis defined six units characterized as: Unit I - Plane Top Relief in Volcanic Spill: shows plane relief with relatively low erosive processes and intemperism; Unit II - Hills in Volcanic Spill: slightly wavy areas underneath the plateau summit; Unit III - Hills and Small Size Hills in Volcanic Rock: formed by strongly wavy relief and within scarps; Unit IV - Small Size Hills in Sandstone: composed by isolated small size hills with origin associated to the existence of united sandstones that keeps the plane top relief; Unit V - Hills in Sandstone: Relief of hills located at the medium and low course of the streams, with the occurrence of accelerated erosive processes which produce sand dunes and accelerated erosions, and sometimes within blooming of united sandstones in the half-slope or in the top; Unit VI - Plane Relief in Low Altitude: Relief of plane topography that predisposes the superficial dynamic processes, generating the accumulation of sediments as well as the formation of fluvial terraces. The fragility of the natural systems, in face of the antropic interventions, is largely associated to its genetic characteristics. Thus, the geomorphologic analysis in the environmental studies is a tool for the maintainable planning of the activities introduced in the region.
\end{abstract}

Keywords: Hidrographic Basins; Mapping; Geomorfological Units.

Trabalho realizado com apoio FAPERGS n. ${ }^{\circ}$ 05/18123 - CNPq 470432/2006-3.

1 Geografia Bacharel; LAGEOLAM - Laboratório de Geologia Ambiental; Departamento de Geociências/CCNE; Universidade Federal de Santa Maria - Santa Maria, RS; mestranda em Geografia - UFRGS; e-mail: leiarighi@yahoo.com.br

2 Prof. do Dep. de Geociências; LAGEOLAM - Laboratório de Geologia Ambiental Departamento de Geociências/CCNE; Universidade Federal de Santa Maria - Santa Maria, RS; e-mail: lesrobaina@yahoo.com.br 
RIGHI, E.; ROBAINA, L. E. de S. Arroios Jaguarí-Mirim, Inhadiju e Piquiri em seu...

\section{INTRODUÇÃO}

O relevo é um produto do antagonismo de forças internas, atuando através do arranjo estrutural das litologias e também por agentes externos, comandados pela dinâmica superficial, que produzem o desgaste da estrutura e geram a esculturação das formas. A tipologia topográfica que ele assume é dinâmica e se inter-relaciona com os demais componentes do espaço geográfico.

Sob essa perspectiva, os Mapeamentos Geomorfológicos possuem um caráter multidisciplinar para a compreensão das estruturas espaciais, como também para o planejamento ambiental. Assim, o presente trabalho tem por objetivo identificar, definir e mapear as diferentes feições morfodinâmicas presentes nas Bacias Hidrográficas dos Arroios Jaguarí Mirim, Inhadiju e Piquiri, localizadas no Oeste do Rio Grande do Sul - Brasil.

Geograficamente, a área de estudo localiza-se entre as latitudes $29^{\circ} 18^{\prime} 16^{\prime \prime}$ e $29^{\circ} 42^{\prime} 35^{\prime \prime}$ Sul e entre as longitudes $55^{\circ} 08^{\prime} 12^{\prime \prime}$ e $54^{\circ} 44^{\prime} 28^{\prime \prime}$ Oeste (Figura 01). Compreende uma área total de $940 \mathrm{~km}^{2}$, estendendose pelos municípios de São Francisco de Assis, Nova Esperança do Sul, Santiago e Jaguarí.

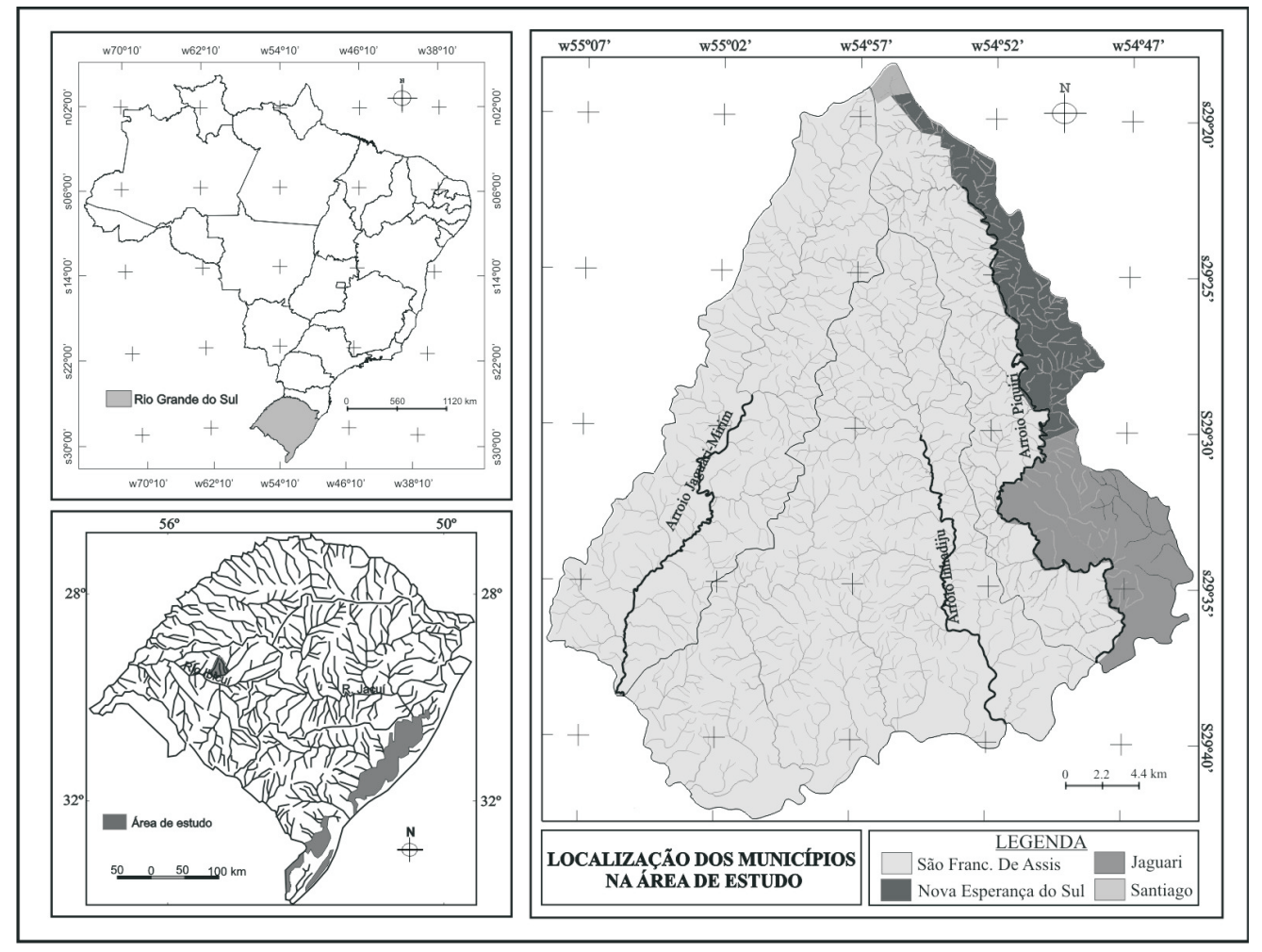

FIGURA 1 - LOCALIZAÇÃO DA ÁREA DE ESTUDO

Essas bacias estão inseridas transicionalmente entre duas unidades geomorfológicas no Estado do Rio Grande do Sul: o Planalto sul-riograndense e a Depressão Periférica. A faixa de transição entre essas duas unidades é definida como Rebordo do Planalto (MÜLLER FILHO, 1970).

Segundo Nimer (1989), o clima no Estado é classificado como subtropical. O regime pluviométrico anual segundo Suertegaray (2001) da região fica entre 1200 e $2000 \mathrm{~mm}$.

De acordo com Streck et al (2002) os solos encontrados em virtude da alteração dos derrames vulcânicos e dos arenitos podem ser classificados em três tipos principais: neossolos litólicos, latossolos e argissolos nas áreas planas e solos hidromórficos junto à rede de drenagem.

A vegetação predominante é composta por gramíneas e gramináceas, compondo os campos, que se entremeiam inclusive às áreas florestais. A vegetação arbórea ocorre nas áreas do Rebordo, nas encostas mais íngremes dos cerros e junto à rede de drenagem como mata ciliar. 
RIGHI, E.; ROBAINA, L. E. de S. Arroios Jaguarí-Mirim, Inhadiju e Piquiri em seu...

\section{METODOLOGIA}

O presente trabalho desenvolveu-se a partir da técnica de mapeamento geoambiental do Laboratório de Geologia Ambiental (LAGEOLAM/UFSM), desenvolvida por Trentin e Robaina (2005), que se baseia na possibilidade de divisão da área estudada em unidades homogêneas, conforme apresentado na figura 2 .

$\mathrm{A} 1^{\circ}$ etapa constituiu-se no levantamento teóricometodológico dos trabalhos e investigações realizadas na região, levantamentos cartográficos usando-se como base as cartas topográficas do exército de Nova Esperança do Sul (SH.21-X-D-II-3), Vila Kramer (SH.21X-D-I-4), São Francisco de Assis (SH.21-X-D-IV-2) e
Boa Esperança (SH.21-X-D-VI), na escala 1:50000, interpretação de imagem de radar - SRTM (2001) e trabalhos de campo.

$\mathrm{A} 2^{\mathrm{a}}$ etapa da pesquisa foi elaborada através da construção de mapas temáticos da rede de drenagem, relevo e litologias (imagens de satélite e trabalho de campo). O mapa de solos foi compilado através de informações físicas de campo que possibilitaram a definição das características de textura, espessura, cor e proximidade com a rocha. A análise também levou em consideração o relevo e o substrato litológico.

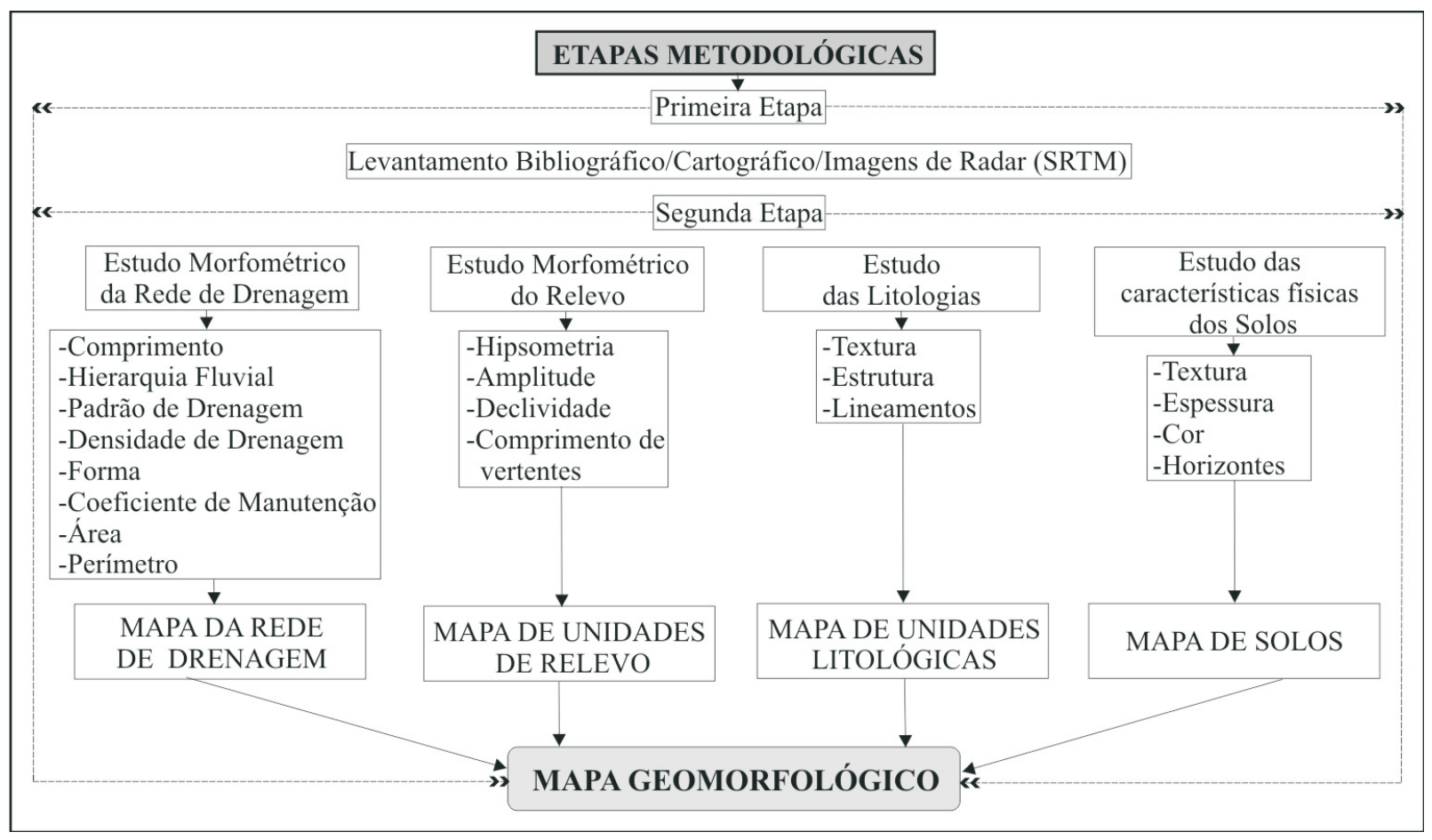

FIGURA 2 - FLUXOGRAMA METODOLÓGICO

A etapa final caracterizou-se com a análise em conjunto desses atributos permitindo definir as Unidades Geomorfológicas, onde são definidas áreas com características semelhantes na tentativa de demonstrar as variáveis de forma integrada.
A compilação dos resultados foi elaborada utilizando o SIG, software SPRING (Sistema de Processamento de Informações Georreferenciadas) 4.2, desenvolvido pelo INPE (Instituto Nacional de Pesquisas Espaciais) e Corel Draw 12, desenvolvido pelo Corel Inc. 
RIGHI, E.; ROBAINA, L. E. de S. Arroios Jaguarí-Mirim, Inhadiju e Piquiri em seu...

\section{RESULTADOS}

\section{REDE DE DRENAGEM}

A área total em estudo é de aproximadamente $940 \mathrm{~km}^{2}$, tendo a bacia do arroio Jaguarí-Mirim uma área de $261,472,973 \mathrm{~km}^{2}$, a área compreendida do arroio Inhadiju é de $433,164,289 \mathrm{~km}^{2}$ e do arroio Piquiri de $228,447,955 \mathrm{~km}^{2}$.

A rede de drenagem das três bacias (Figura 3 ) apresentou uma hierarquia de $5^{\text {a }}$ ordem, os cursos fluviais possuem comprimento total de $1.234 .437,53 \mathrm{~km}$, distribuído em 1.425 canais de escoamento.
A área apresenta uma densidade de drenagem de $1,29 \mathrm{~km} / \mathrm{km}^{2}$, o que indica segundo Beltrame (1994) um grau mediano de escoamento e infiltração. A densidade de drenagem do arroio Jaguarí Mirim é de 1,62 $\mathrm{km} / \mathrm{km}^{2}$ e do arroio Inhadiju $1,68 \mathrm{~km} / \mathrm{km}^{2}$, enquanto a densidade de drenagem do arroio Piquiri apresentou $2,069 \mathrm{~km} / \mathrm{km}^{2}$.

A densidade hidrográfica do arroio Jaguarí Mirim apresentou frequência de 0,0014 cursos d'água por km², o arroio Inhadiju 0,0015 e o arroio Piquiri 0,0018.

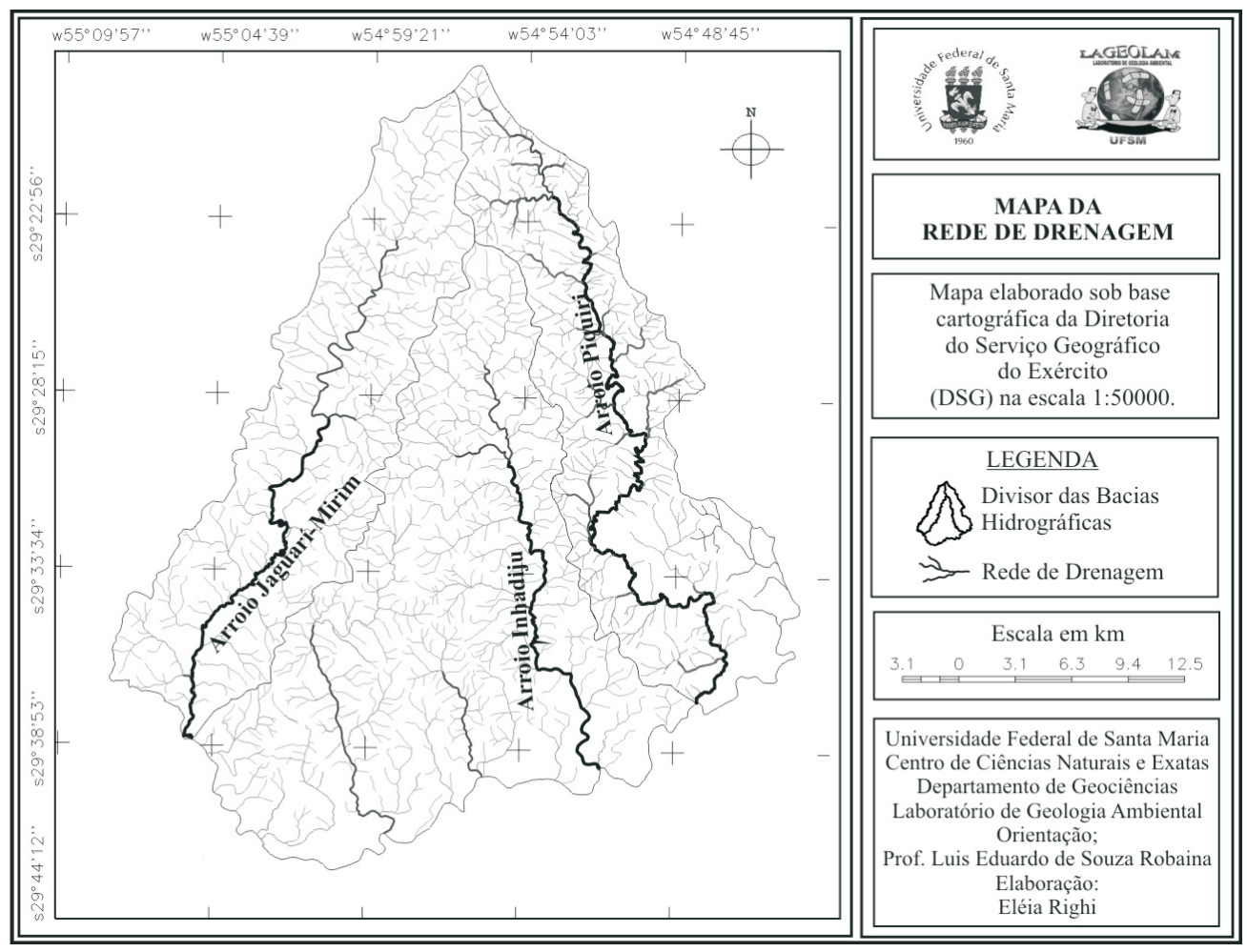

FIGURA 3 - MAPA DA REDE DE DRENAGEM

O relativo maior escoamento superficial do Piquiri, provavelmente está associado às características do substrato presente, caracterizado predominantemente por uma sequência de arenitos fluviais e lacustres de granulação fina a muito fina muito homogênea, algumas vezes siltitos.

O índice de circularidade é um parâmetro utilizado para indicar a susceptibilidade a processos de inundação. A Bacia Hidrográfica do arroio Jaguarí Mirim,
Inhadiju e do arroio Piquiri possuem respectivamente os índices 0,29,0,36 e 0,30, caracterizando bacias alongadas, próximas de retangulares, muito estreitas, sendo menos sujeitas a enchentes.

O padrão de drenagem, caracterizado pelo arranjo espacial dos canais apresenta um comportamento retangular-dendrítico refletindo o controle estrutural da área de estudo. 
RIGHI, E.; ROBAINA, L. E. de S. Arroios Jaguarí-Mirim, Inhadiju e Piquiri em seu...

\section{RELEVO}

A análise dos atributos do relevo permitiu a individualização de seis unidades homogêneas de relevo, conforme pode se identificar na figura 4.

$O$ relevo de vertentes alongadas e planas ocorre de forma mais significativa próximo ao baixo curso dos Arroios e na planície de inundação do Rio Jaguarí, onde estes três arroios deságuam.

No baixo curso dos arroios, existem colinas com relevo suavemente ondulado, constituindo as áreas de divisores internos entre as bacias hidrográficas.

No Rebordo do Planalto, ocorrem formas de morros e morrotes e vertentes escarpadas.

No alto curso dos arroios ocorrem formas de vertentes onduladas constituindo colinas com morrotes associados.

As áreas mais elevadas presentes nas bacias encontram-se sobre o planalto, e são formadas pelos topos planos das colinas e morrotes.

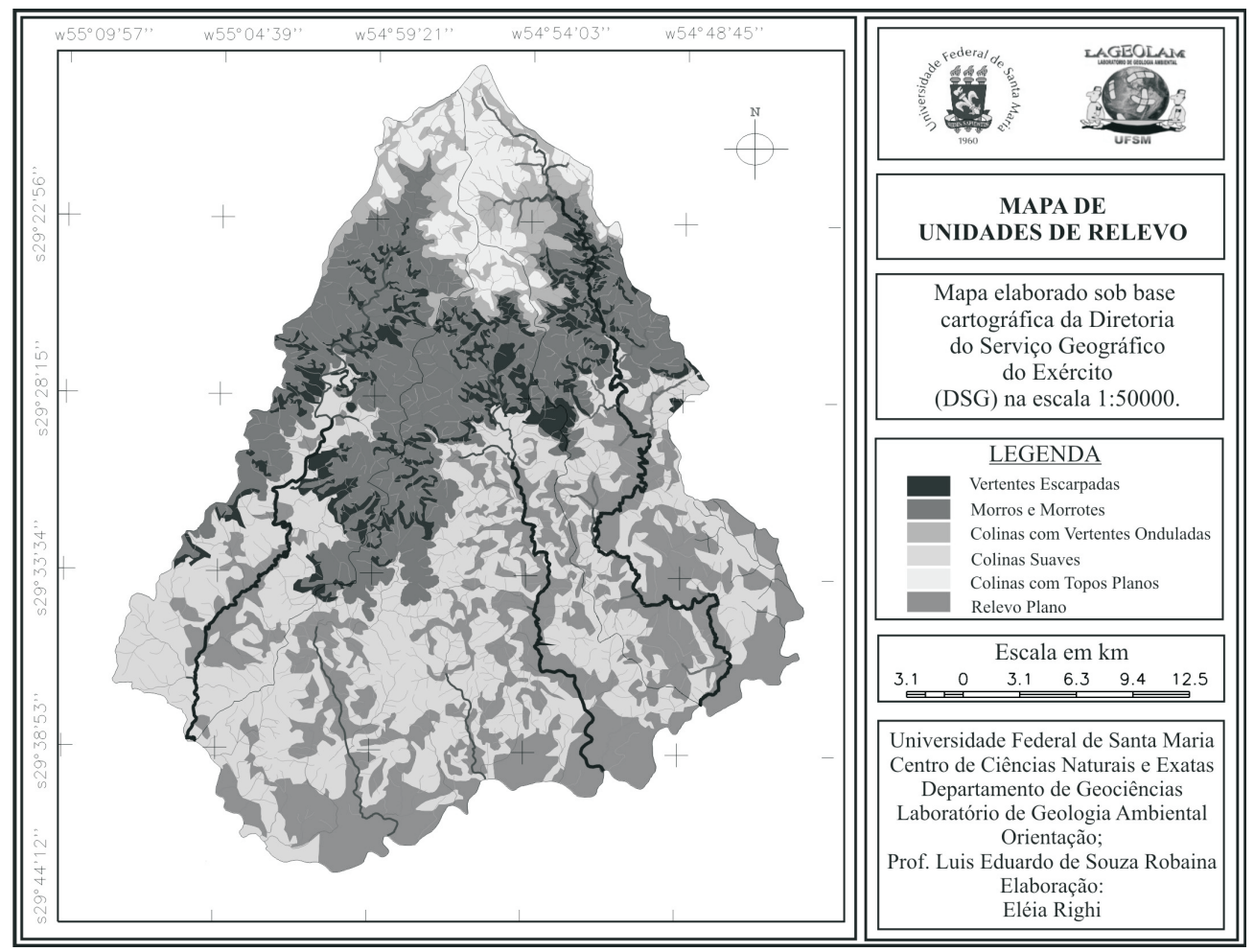

FIGURA 4 - MAPA DE UNIDADES DE RELEVO

\section{LITOLOGIAS}

As litologias (Figura 5) mais antigas da área estão representadas por arenitos definidos como fluviais e lacustres. Caracterizam-se por arenitos de granulação fina a muito fina muito homogênea, algumas vezes siltitos. A constituição mineralógica é quartzo, feldspatos e as micas, que ocorrem, preferencialmente, nos arenitos mais finos. Possui matriz fina, síltico-argilosa, o cimento pode ser de sílica ou óxido/hidróxido de ferro. Quando alterados originam um fissuramento em forma de pastilha.

O substrato que segue relaciona-se, provavelmente, a um sistema de sedimentação fluvial. Esse pacote resultou em uma mineralogia mal selecionada quartzosa, areno-granulosa de coloração avermelhada. Os grânulos de sílica e quartzo arredondados são esparsos predominantemente leitosos variando desde milímetros até cerca de três centímetros. 
RIGHI, E.; ROBAINA, L. E. de S. Arroios Jaguarí-Mirim, Inhadiju e Piquiri em seu...

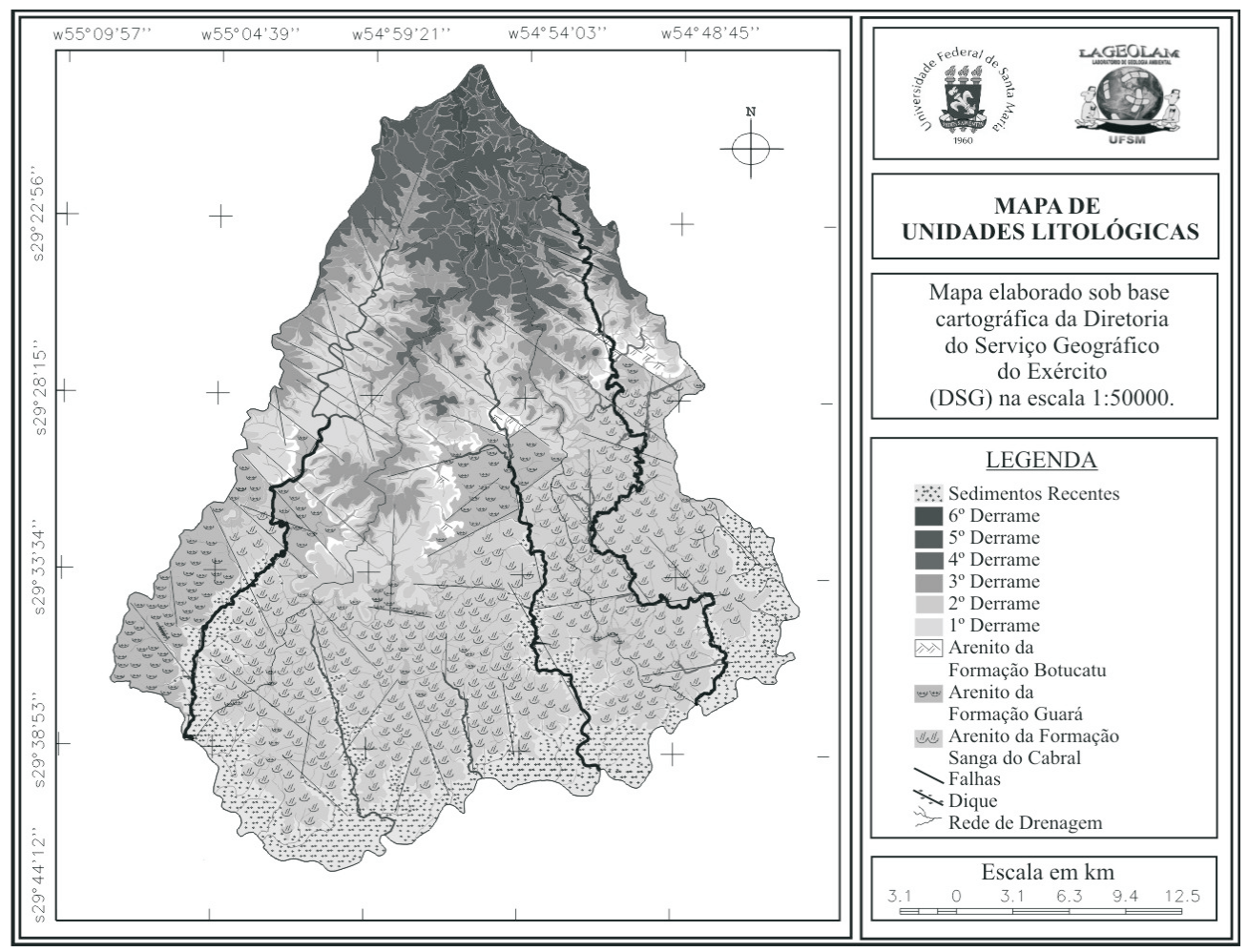

FIGURA 5 - MAPA DE UNIDADES LITOLÓGICAS

Scherer et al (2002) classificam essa sequência como Neojurássica, correspondendo litoestratificamente à Formação Guará.

A sequência de arenito sobreposta está representada pela Formação Botucatu que reflete as condições ambientais e os processos que lhe deram origem dentro de um sistema semiárido. Destaca-se sua alta seleção granulométrica (fina a média), com grãos bem arredondados, em geral foscos e apresentando alta esfericidade. Os sedimentos quartzosos, contendo feldspatos, apresentam coloração avermelhada alternada com camadas mais claras (rosada) provavelmente pela remoção do óxido de ferro.

O panorama magmático é complexo, sendo registrado pelas observações de campo provavelmente seis derrames vulcânicos, fazendo parte da formação Serra Geral da Bacia do Paraná. Cada derrame reflete um aspecto morfológico do terreno, que se apresenta especialmente ligado a fatores climáticos atuais e passados, diferenciando-se o tipo de modelado, de formação superficial e do comportamento das drenagens.
Os depósitos aluviais recentes são significativos em decorrência dos Arroios e da planície de inundação do Rio Jaguarí. Este material aparece em alguns locais nas médias vertentes na forma de terraços fluviais suspensos, indicando um nível mais elevado do antigo leito fluvial.

As vertentes íngremes que constituem o rebordo do Planalto formam depósitos coluviais de coloração acastanhada a preta, constituindo acumulações de materiais finos e grosseiros.

As faixas litológicas estão inseridas em blocos delimitados por importantes falhas que truncam e refletem lineamentos direcionais. Estes direcionamentos ocorrem preferencialmente em sentido SE/NW ao Norte e ao Sul, destacam-se também os direcionamentos N/S, onde estão localizadas as principais drenagens.

Estes lineamentos têm importante contribuição na evolução da topografia, bem como no controle da rede de drenagem, marcando zonas variáveis em tectonismo, dentro de um sistema geológico mais antigo. 


\section{DISTRIBUIÇÃO DOS SOLOS}

A trajetória evolutiva dos solos (Figura 6) distribuise sobre a área com uma visível predominância dos argissolos que se localizam no baixo curso dos arroios, junto aos divisores internos das bacias, como também no topo do Planalto, apresentando profundidade média, de coloração avermelhada e às vezes cinza, argilosos (horizonte B textural bem desenvolvido), bem drenados e desenvolvidos a partir de substratos areníticos, principalmente, da Formação Sanga do Cabral e de substrato de rochas vulcânicas.

Os Neossolos Litólicos localizam-se na porção central da área associados às rochas vulcânicas, em relevo forte ondulado, com pedregosidade e afloramentos de rochas. Associados ocorrem os cambissolos.

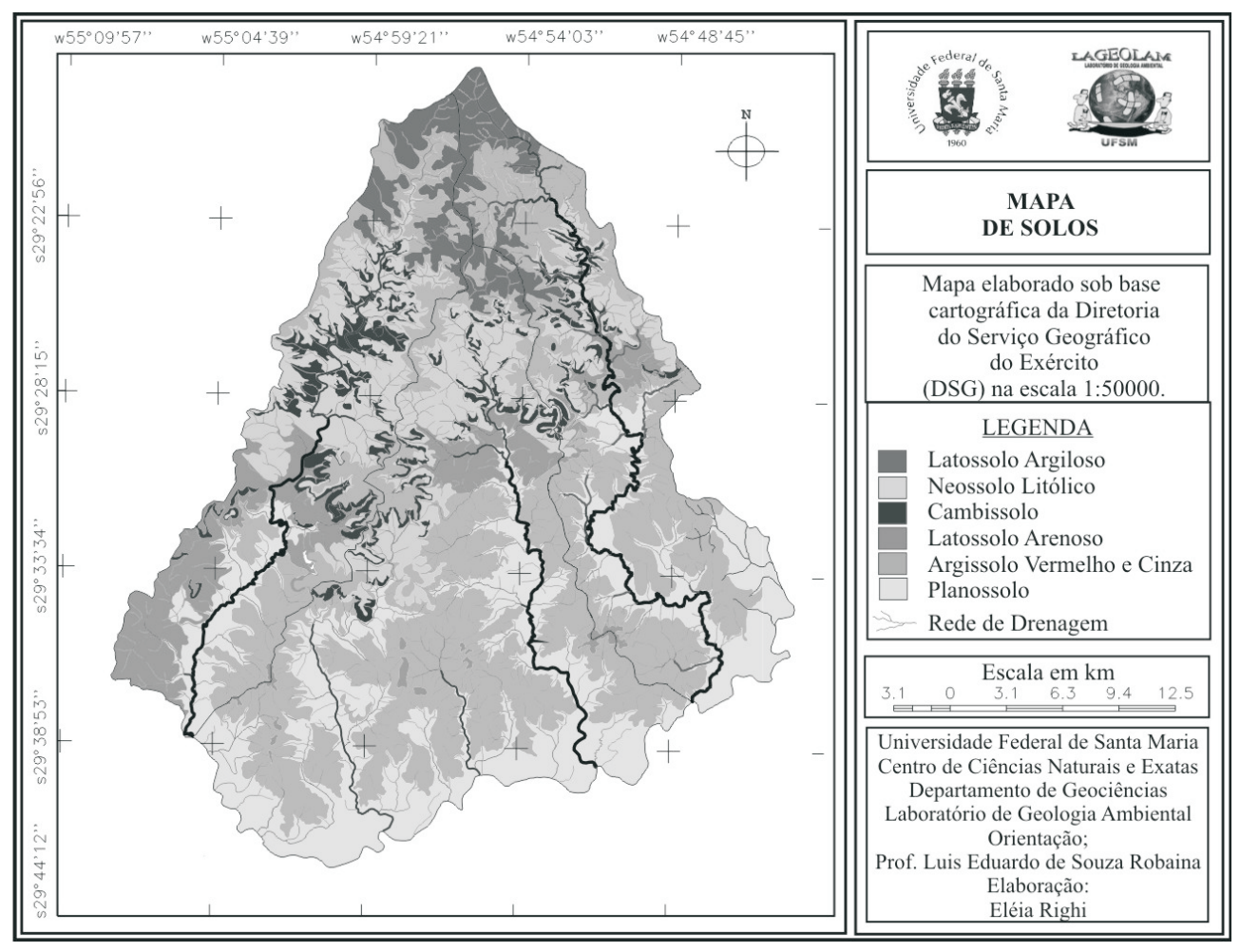

FIGURA 6 - MAPA DE SOLOS

Sob substratos areníticos da formação Guará, ocorrem latossolos arenosos, homogêneos, profundos, bem drenados, porosos e de coloração vermelha. Também ocorrem latossolos argilosos localizados no topo do Planalto e no médio curso dos arroios.

Os planossolos são encontrados em áreas de várzea, com relevo plano a suavemente ondulado. Ocorrem associados às sequências de substrato arenítico próximos das drenagens.

\section{INTEGRAÇÃO DOS RESULTADOS: UNIDADES GEOMORFOLÓGICAS}

As Unidades Geomorfológicas distribuem-se pela área, perfazendo um total de seis tipos distintos, como pode ser verificado nas figuras 7 e 8; e tabela 1 . 


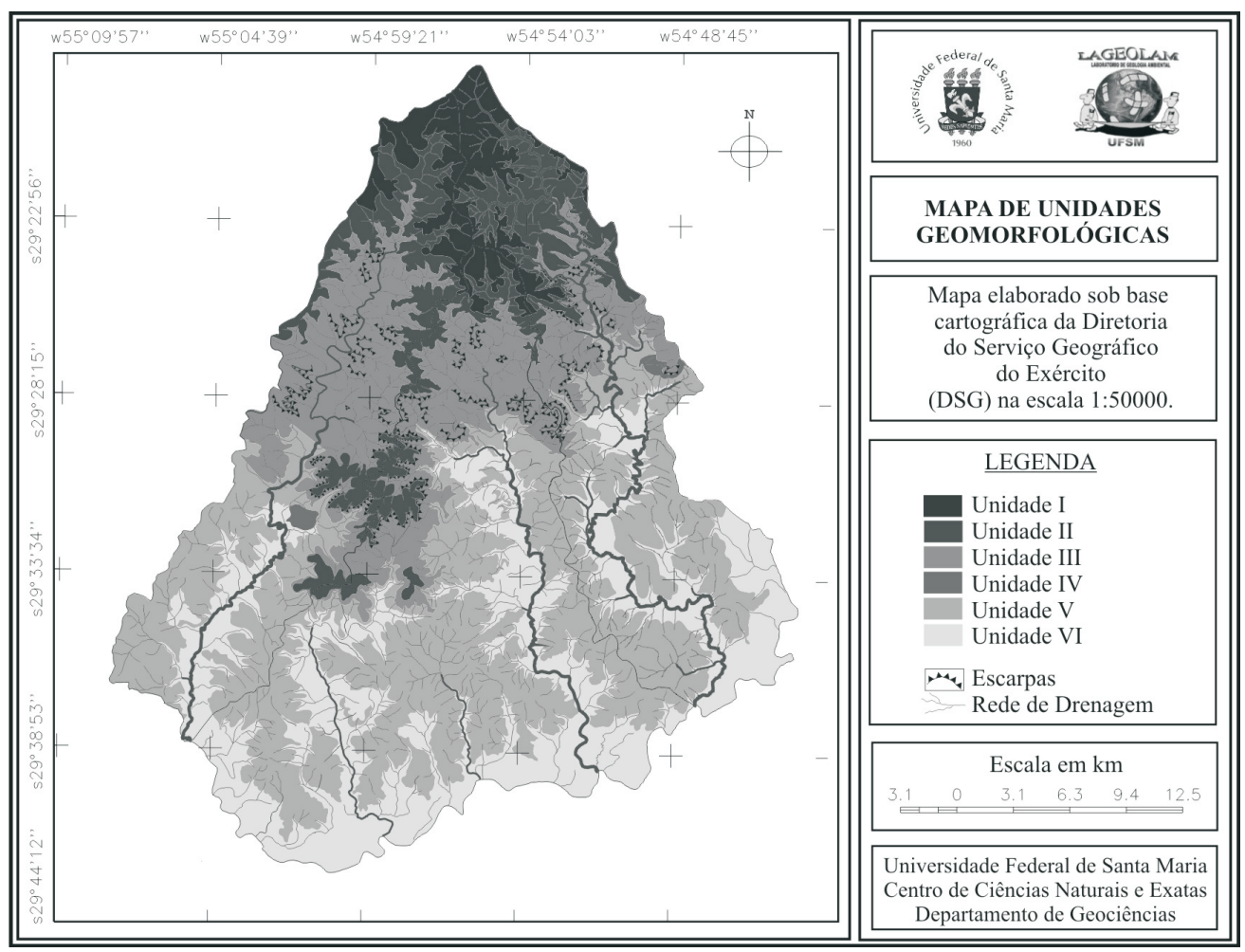

FIGURA 7 - MAPA DE UNIDADES GEOMORFOLÓGICAS

No Relevo de Topo Plano em Derrame Vulcânico formam-se as nascentes dos cursos de água dos arroios Jaguarí-Mirim e Piquiri, constituindo a Unidade I. Os processos erosivos são relativamente baixos, ocorrendo de forma mais significativa intemperismo. Nessas áreas de topos, desenvolvem-se solos melhor desenvolvidos (argissolos e latossolos argilosos). A vegetação encontra-se ligada ao ambiente marcado pela pecuária extensiva a expansão da lavoura de soja e alguns cultivos de média propriedade.

A Unidade II são as Colinas em Derrame Vulcânico, constituindo as áreas suavemente onduladas do topo do Planalto, sob substrato vulcânico. Nesses locais formam-se argissolos, associadas à erosão de baixa intensidade, ocorrendo apenas pequenos ravinamentos. A cobertura vegetal é formada por campos, em grandes e médias propriedades, sendo paralelamente usados para as grandes lavouras cultivadas ciclicamente por soja e milho.

Os Morros e Morrotes em Derrame Vulcânico compõem a Unidade III com vertentes fortemente onduladas e escarpadas, formando neossolos litólicos e cambissolos. 
RIGHI, E.; ROBAINA, L. E. de S. Arroios Jaguarí-Mirim, Inhadiju e Piquiri em seu...

TABELA 1 - CARACTERÍSTICAS DAS UNIDADES GEOMORFOLÓGICAS

\begin{tabular}{|c|c|c|c|c|}
\hline $\begin{array}{c}\text { Unidades } \\
\text { Geomorfológicas }\end{array}$ & Morfometria & Morfologia & Substrato & $\begin{array}{l}\text { Processo } \\
\text { Superficial } \\
\text { Principal }\end{array}$ \\
\hline Unidade I & $\begin{array}{c}\text { Declividade } \\
\quad<2 \% \\
\text { Altitudes: }>360\end{array}$ & Plano & $\begin{array}{l}\text { Derrame } \\
\text { Vulcânico }\end{array}$ & $\begin{array}{l}\text { Intemperismo } \\
\text { e pequenos } \\
\text { ravinamentos }\end{array}$ \\
\hline Unidade II & $\begin{array}{c}\text { Declividade: } 5 \text { - } \\
15 \% \\
\text { Altitudes: }>360 \mathrm{~m}\end{array}$ & Relevo ondulado & $\begin{array}{l}\text { Derrame } \\
\text { Vulcânico }\end{array}$ & $\begin{array}{l}\text { Erosão com } \\
\text { pequenos } \\
\text { ravinamentos }\end{array}$ \\
\hline Unidade III & $\begin{array}{c}\text { Declividade }>15 \% \\
\text { Altitude: } 160-360 \\
m\end{array}$ & $\begin{array}{l}\text { Fortemente } \\
\text { ondulado e } \\
\text { escarpada }\end{array}$ & $\begin{array}{l}\text { Derrame } \\
\text { Vulcânico }\end{array}$ & $\begin{array}{c}\text { Movimento } \\
\text { de Massa e } \\
\text { deslocamento de } \\
\text { blocos }\end{array}$ \\
\hline Unidade IV & $\begin{array}{c}\text { Declividade }>15 \% \\
\text { Altitudes: } 100-240 \\
m\end{array}$ & Morrotes Isolados & $\begin{array}{l}\text { Arenitos } \\
\text { Fluviais e } \\
\text { Botucatu }\end{array}$ & $\begin{array}{c}\text { Movimentos } \\
\text { de massa e } \\
\text { processos } \\
\text { erosivos com } \\
\text { geração de } \\
\text { ravinas e } \\
\text { voçorocas na } \\
\text { base. }\end{array}$ \\
\hline Unidade V & $\begin{array}{l}\text { Declividades: }<5 \% \\
\text { Altitudes: }<240 \text { m }\end{array}$ & $\begin{array}{c}\text { Suavemente } \\
\text { ondulado }\end{array}$ & $\begin{array}{l}\text { Arenitos } \\
\text { Botucatu, } \\
\text { Fluviais e } \\
\text { Micáceos }\end{array}$ & $\begin{array}{c}\text { Processos } \\
\text { Erosivos com } \\
\text { geração de } \\
\text { ravinas e } \\
\text { voçorocas }\end{array}$ \\
\hline Unidade VI & $\begin{array}{c}\text { Declividade: }<2 \% \\
\text { Altitudes } 180 \mathrm{~m}\end{array}$ & $\begin{array}{l}\text { Fundo de vale } \\
\text { com relevo plano }\end{array}$ & $\begin{array}{l}\text { Sedimentos } \\
\text { Recentes }\end{array}$ & Acumulação \\
\hline
\end{tabular}

As vertentes escarpadas constituem uma característica morfométrica que caracteriza essa unidade. Nas porções de base das vertentes íngremes formamse depósitos coluviais de coloração acastanhada a preta, constituindo acumulações de materiais finos e grosseiros, transportados vertente abaixo por processos de movimentação de massa e escoamento superficial. O uso do solo é realizado em locais de fácil acesso, predominando as pequenas propriedades.

A Unidade IV definida pelos Morrotes em Arenito compõe-se de arenitos fluviais e Botucatu apresentando uma maior coesão do material. A presença de óxido de ferro como cimento em camadas do arenito forma um relevo de topos planos. Na base sob solos arenosos encontram-se processos erosivos como ravinas e voçorocas.

As encostas apresentam declividades superiores a $15 \%$, com presença de vegetação nativa característica de substratos areníticos e por vezes gramíneas e gramináceas.

A Unidade V são as Colinas em Arenito, áreas suavemente onduladas, sendo a mais significativa localizada ao médio e baixo curso dos arroios. Esses locais de arenitos friáveis possuem em seu interior os 
relevos mais intensivamente afetados pelos processos de dissecação da superfície. A exposição do solo pelo excesso de uso ligado ao pastoreio e aliada aos ventos intensos, tende a intensificar o surgimento dessas áreas gerando areais e voçorocas.

Nesta unidade pode ser encontradas porções de arenitos finos com alterações na forma de pastilhas formando argissolos, porções de arenitos médios, onde a pouca presença de ligantes indica condições relativamente menores de resistência aos processos erosivos, formando latossolos arenosos e porções formadas por arenito fluvial no topo e arenito mais fino na base, gerando argissolos e constituindo os divisores internos nas baixas altitudes das bacias.

Os processos erosivos formam-se de forma remontante, gerando ravinas e voçorocas, e às vezes, a erosão avançada também esta associada a cabeceiras de drenagem ou ligadas a degraus compostos por arenitos cimentados no topo da colina.
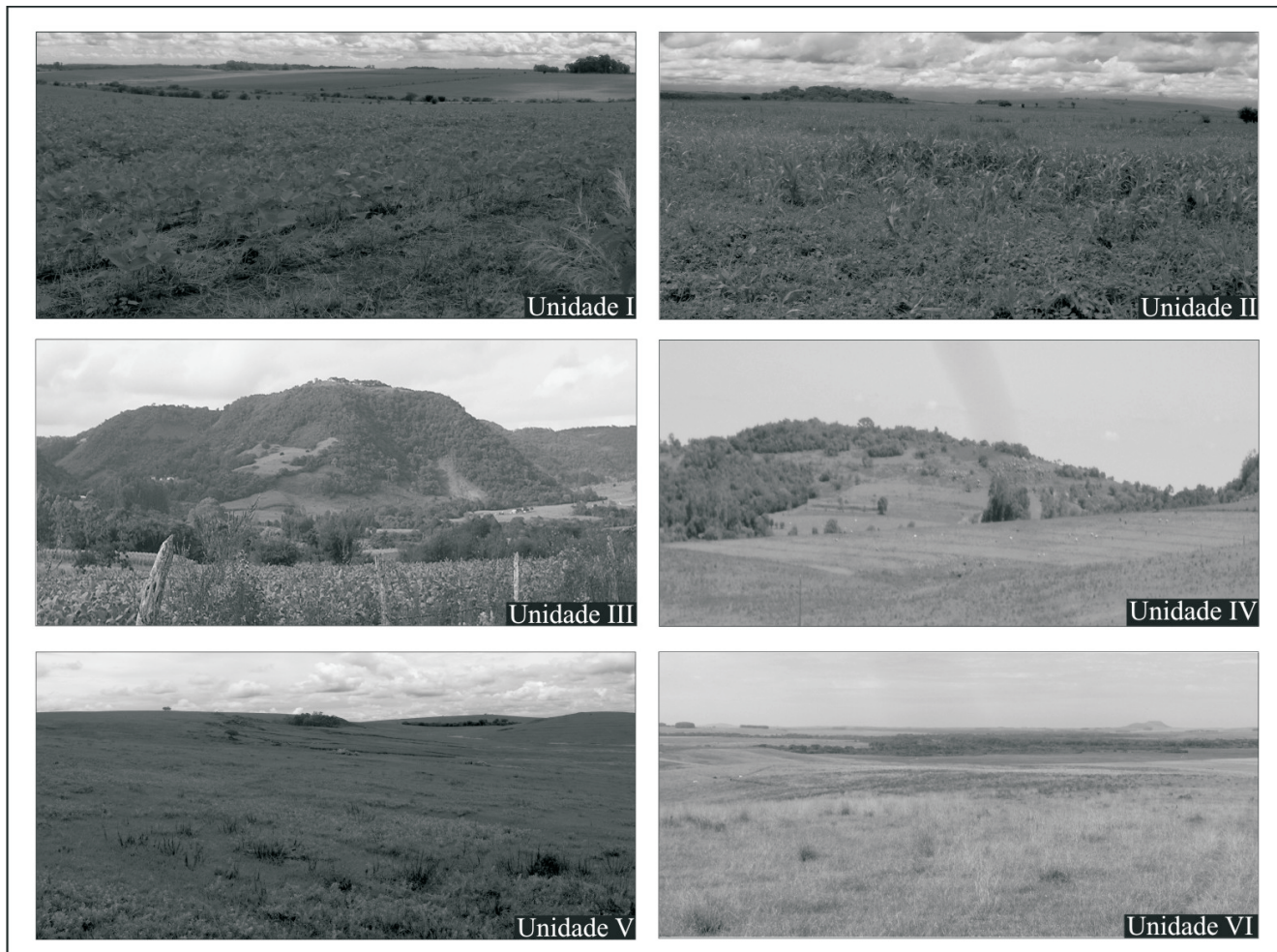

FIGURA 8 - ILUSTRAÇÃO DAS UNIDADES GEOMORFOLÓGICAS

A vegetação arbórea está presente sob a forma de mata ciliar bastante degradada. Nessas áreas encontram-se grandes propriedades destinadas principalmente para a pecuária de corte, mas nos últimos anos verificam-se novas possibilidades apresentadas para os grandes proprietários através do desenvolvimento de outras atividades agrícolas, particularmente a cultura da soja, como também o arroz irrigado de várzea, sendo produzido em larga escala na região.
A Unidade VI compreende a segunda maior área formando um Relevo Plano em Baixa Altitude, que predispõe os processos de dinâmica superficial gerando acumulação de sedimentos e a formação de terraços fluviais. Os depósitos recentes formados por materiais retrabalhados moderadamente classificados, acumulam-se principalmente na planície de inundação do rio Jaguarí. Predominam planossolos com baixa capacidade de drenagem favorecendo o cultivo de arroz irrigado e pecuária extensiva. 
RIGHI, E.; ROBAINA, L. E. de S. Arroios Jaguarí-Mirim, Inhadiju e Piquiri em seu...

\section{CONSIDERAÇÕES FINAIS}

Os elementos que delimitam as unidades apresentam-se compondo superfícies articuladas aos processos de dinâmica superficial, mantendo uma identidade única na paisagem. Dessa forma, o mapeamento de Unidades Geomorfológicas possibilita posteriores

\section{REFERÊNCIAS}

BELTRAME, A. V. Diagnóstico do Meio Físico de Bacias Hidrográficas: Modelo e Aplicação. Florianópolis: Ed. da UFSC, 1994.

MÜLLER FILHO, I. L. Notas para o Estudo da Geomorfologia do Rio Grande do Sul. UFSM, Santa Maria, 1970.

NIMER, E. Climatologia do Brasil. 2. ed. Rio de Janeiro: IBGE, 1989.

SCHERER, C.; FACCINI, U.; LAVINA, E. Arcabouço Estratigráfico do Mesozóico da Bacia do Paraná. In: Geologia do RS. Porto Alegre: Editora da Universidade UFRGS, 2002. p. 335-354. trabalhos de mapeamentos geoambientais, bem como para planejar de forma sustentável as atividades implantadas na região, a fim de mitigar a degradação e o impacto ambiental.
STRECK, E. V.; KAMPF, N.; DALMOLIN, R. S. D.; KLAMT, E.; NASCIMENTO, P. C. de; SCHNEIDER, P.; GIASSON, E.; PINTO, L. F. S. Solos do Rio Grande do Sul. Porto Alegre: UFRGS, 2002.

SUERTEGARAY, D. M. A.; GUASSELLI, L. A.; VERDUM, R. Atlas da arenização: Sudoeste do Rio Grande do Sul. Porto Alegre: Ed. da UFRGS, 2001.

TRENTIN, R.; ROBAINA, L. E. S. Metodologia para mapeamento Geoambiental no Oeste do Rio Grande do Sul. In: CONGRESSO BRASILEIRO DE GEOGRAFIA FÍSICA APLICADA, 11., 2005, São Paulo. Anais... São Paulo, 2005. p. $3606-3615$. 
